\title{
BREASTFEEDING PRACTICES AFTER KANGAROO MOTHER METHOD IN RIO DE JANEIRO: THE NECESSITY FOR HE ALTH EDUCATION AND NURSING INTERVENTION AT HOME
}

\section{A prática da amamentação após o método mãe canguru no Rio de Janeiro : a necessidade de educação em saúde e intervenção de Enfermagem no domicílio}

\section{La práctica de amamantar después del Método Mamá Canguro en Río de Janeiro: La necesidad de educación en salud e intervención de enfermería en el domicilio}

Ivone Evangelista Cabral ${ }^{1} \quad$ Danielle Groleau ${ }^{2}$

\section{RESUMO}

0 "ensino-aprendizagem" integra o Método Mãe Canguru (MMC) brasileiro para promover as habilidades maternas na amamentação de bebês prematuros ou baixo peso. Por desconhecermos se o que foi ensinado integrou o círculo interno da família, nosso objetivo foi analisar como esse conhecimento sobre amamentação exclusiva foi incorporado no contexto dos domicílios. A pesquisa participante aconteceu no domicilio de 11 grupos de mães, familiares e vizinhos. 0 saber local dos vizinhos e familiares substituiu o conhecimento ensinado à mãe no MMC e mudou a alimentação desses bebês. A educação em saúde deve estenderse para além do hospital e incluir os familiares e pessoas significativas.

Palavras-chave: Cuidado pós-natal. Saúde da criança. Enfermagem pediátrica. Aleitamento materno

\section{Abstract}

IThe "teaching-leaning" is part of the Brazilian Kangaroo Mother Method with the objective of increasing skills of mother's breastfeeding infants with special health needs. Nevertheless, we do not know if this knowledge was embodied in the family inner circle, so we aimed at identifying and analyzing how this medical knowledge was incorporated in the context of infants' homes. Participatory research was developed at home with eleven groups of mother, family members and neighbors. Local knowledge of neighbors' and family members' replaced the medical knowledge and changed infant feeding practices. Health education should be implemented beyond hospital and include family members.

\section{Resumen}

La "enseñanza-aprendizaje" integra el Método Mamá Canguro brasileño para promover las habilidades maternas en la acción de amamantar a bebés prematuros o con bajo peso. Por desconocer si lo que fue enseñado integró al círculo interno de la familia, nuestro objetivo fue el de analizar como ese conocimiento sobre lactancia exclusiva fue incorporado en el contexto de los domicilios. La investigación sucidió en el domicilio de 11 grupos de madres, familiares y vecinos. El saber local de los vecinos y familiares substituyó el conocimiento enseñado a la madre en el Método y cambió la alimentación de esos bebés. La educación en salud debe extenderse más allá del hospital e incluir a los familiares y personas significativas. 


\section{INTRODUCTION}

The Brazilian healthcare policy has integrated breastfeeding promotion into Kangaroo Mother Method ${ }^{(1-2)}$ to maximize the care and well-being of premature and low birth weight infants. These infants with special health needs are fragile and require more attention and vigilance ${ }^{(3-4)}$ of the whole family, either at hospital or at home. The two interventions of Kangaroo Mother Method involves clinical controlled guidelines and humanizing approach of developing attachment between mothers and infants $^{1-2}$. Besides the clinical and psychological approaches of Kangaroo Mother Method, the teaching-learning process is based on scientific knowledge implemented by explanation, supporting, and demonstrations of procedures. This third intervention aims at improving the mothers' skills in caring for infants with special health needs, and influencing maternal decision of breastfeeding them exclusively ${ }^{3-5}$. Mothers are taught how to breastfeed and recognize their infant's signals of ill-being given their special needs related to premature birth and/or insufficient weight.

Notwithstanding the intense promotion of breastfeeding and the literature review, it is unknown whether the knowledge taught to mothers regarding their infants with special health needs has been integrated into the family environment. Consequently, we investigated how mothers' knowledge, about breastfeeding, were embodied in the family circle, after they were delivered from "Kangaroo Mother" Unit. Therefore, our goals were to identify the teaching-learning process of breastfeeding skills developed at Kangaroo Mother Method and to analyze the incorporation of this information within the sociocultural context of infants' homes.

The scientific literature as well as information disseminated at international meeting have recommended studying approaches for the promotion of breastfeeding among premature and low birth weight infants ${ }^{6-7}$. Of particular interest is whether the combination of breastfeeding and kangaroo care serves to improve the infants' quality of life. Most of the scientific research regarding kangaroo care and/or breastfeeding was done at different hospital settings (Neonatal Critical Care Unit, wards, rooming and outpatient) ${ }^{7}$, rather than in the home environment. Those studies were more focus on clinical management than health education intervention.

In the Brazilian context, the post-neonatal period has been associated with a high childhood mortality rate, increase socioeconomic costs, as well as damage to infant growth and development. The relationship between the condition at childbirth and childhood mortality is interrelated. In 2002, the childhood mortality rate was 19.3 per thousand live births with perinatal affections (e.g. hypoxemia, prematurity, low birth weight) responsible for the highest proportional mortality (61.5\%). In addition, these affections were the second leading cause of hospitalization (26.7\%) among infants. ${ }^{8-9}$
Exclusive breastfeeding is recommended for all infants under six months of age, from a more complex level of assistance (critical care) to health promotion (Local Health Centers). The Brazilian Program for Breastfeeding Incentive - Programa Nacional de Incentivo ao Aleitamento Materno - PNIAM"), intersects several strategies, such as "Baby-Friendly Hospital", "Healthy Born", "Breastmilk Bank", and "Kangaroo Mother Method". Among the Maternity Centre (MC) which have these strategies as a policy of care prepare mothers for taking care of their infants based on scientific knowledge regarding infant care and feeding. The motherhood ideology implicit on the scientific knowledge has contributed for improving mothers role and skill as the infants' caregivers ${ }^{10}$.

In spite of these strong initiatives and policy of care, exclusive breastfeeding only raised in average $2.5 \%$ per year (from $56.9 \%$ to $69.5 \%$ ) during five years (1999-2004) . $^{8}$.

\section{THEORETICAL AND METHODOLOGICAL DESCRIPTION: GIVING VOICE TO THE MOTHERS' GROUP.}

In order to better understand the subjectivity ${ }^{11}$ regarding the research question, a qualitative approach was applied. As a strategy for giving voice to the participants as well as generating data, participatory research was conducted in group dynamics called creative-sensitive method of producing data $^{12}$. This method was inspired by a critical-awareness philosophy and developed from the principles of Paulo Freire's participatory research ${ }^{13}$. It comprised five steps during which, in a successive manner, the participants gradually became involved, engaged and empowered to talk about the generative question brought up by the researcher. By following these steps, we applied two group dynamics: body-knowledge and concrete-knowledge. Both strategies allowed the participants to produce images (drawings, pictures, and videos), texts (keywords, clauses) and/or informal speech through "artbased production", as well as to highlight key expressions, which reflected mothers' knowledge regarding breastfeeding at home. The generative question ("What did you learn about breastfeeding your baby when you were at the critical care unit and the Kangaroo Mother Unit that has helped you to implement this practice at home?") guided the interaction process between the Animator (researcher) and the participants. They also had time to organize their ideas, make connections, and dialogue with each other as well as the Animator

In the first step, the animator guided each participant during his/her individual or collective ABP within the inner of the group following the generative question. Next (2), the group worked together on role-playing (video-recorded by the assistant animator), writing key words and drawings. This art-based production was then presented by the group of participants and served to stimulate the debate during which the animator took notes and coded (e.g., colors and key words) the themes 
according to the common and uncommon care experiences (i.e., breastfeeding, physical and/or medication care, social and/or financial support). In the following step (3), the animator elicited discussion from the group as to its decision of the agreed upon theme that they wished to debate. Once decided, the theme was analysed by the group according to its key words, color coded drawings and/or writings, and daily care experiences as expressed in written, drawn, or role-played form. The fourth step (4) was a combination of utterance, interaction, dialogue, and negotiation which lead the group to further decode the theme into subthemes. This process was reached by encountering the homogeneity among the heterogeneity of speech. Also, the meaning of breastfeeding and caring for infants with health needs at home is brought up by each participant, in response to the generative question, turned into a collective meaning by integrating them as part of their normal day of lives. In the final step (5), participants and animators recoded the subthemes into new themes. The recoding process consisted of systematizing the opposition and complementary meanings behind the medical and family knowledge of breastfeeding in the kangaroo care context of experience. The new themes represented a new intertwined knowledge.

The selection of participants was based on theoretical sampling ${ }^{11}$; i.e., the mothers who participated in the Kangaroo Mother Method were the only individuals presumed reliable to talk about their experiences. Mothers were recruited from two Maternity Centres within the same facility, known as the "Baby Friendly Hospital." Within these settings, these strategies Kangaroo Mother Method, Critical Care Unit, and Breastmilk Bank - were implemented with the objectives of improving the survival of infants and promote breastfeeding. All mothers must be included in the following criteria: (a) primary caregivers, (b) breast-feeders of premature or low birth weight infants discharged from the Kangaroo Mother Unit (KM-Unit) (c) whose babies were enrolled in a follow-up outpatient program, (d) wanted to be involved as a volunteer in the research project, (e) had a telephone number as well as an easily accessible address, and $(f)$ the discharge occurred within the last 30 days.

Recruitment of participants commenced with the researchers consulting registers at both the KM-Unit and followup outpatient setting. Of 51 mothers who were able to breastfeed at home, 23 fulfilled the inclusion criteria and, of those, 11 accepted to participate in the research project as a volunteer, after we called to their phone home. At the first home visit, all mothers were informed of their accepted participation in the project, signed an 'Informed Consent' approved by the Institutional Ethical Review Board at Teaching Hospital, and chose the scheduled home visits for Saturday which was more suitable weekday to meet other family members. The confidentiality of information and personal identification were preserved by using an alphabetic order of letter, a quotation of speeches, non-named the facility they were delivered and so on. The fieldwork was done at 11 households situated within the low income communities (slums) of the Rio de Janeiro. We implemented three home visits between January 2002 and September 2004 in order to implement the group dynamics and evaluate the infant's health.

Each group dynamic varied from 40-150 minutes, decreasing in time as the meetings reached the saturation data stage ${ }^{11}$. Besides, we were also able to immerse ourselves in the mothers' and babies' contexts of living, caring, and breastfeeding at home. The process of interaction between family members, mothers, and babies was observed in their actual living circumstances, such as playing, diaper-changing, administering medication, holding, kangaroo holding, breastfeeding, bottle-feeding, and physical care of the infants. Each household consisted of three to four family caregivers and/or the neighbors.

The narratives were recorded on audiotape, transcribed in verbatim. Afterwards, we gathered these data with art-based production, pictures, field notes in order to set a corpus of text. Thus, the whole empirical material was considered as a discourse, analyzed and interpreted by applying the critical discourse analysis based on two principles ${ }^{14}$ : discourse as a social practice, and the coherence between hegemony and ideology in/and behind the language.

First of all, from the critical discourse analysis, discourse is an extended sample of spoken or written language which emphasizes the interaction between speaker and addressee, or writer and reader. It involves the social processes of producing and interpreting speech and writing, as well as the context in which the language use is situated. Consequently, according to Fairclough ${ }^{14}$ all discourses are a social practice. This understanding helps us to increase the consciousness of the relationship between language and power regarding breastfeeding. In particular, how language gives to and receives contributions from the hegemony. It also revealed the ideology embodied in the utterances, that is, the meaning of saying from which social place.

Secondly, the applicability of hegemony means the domination of one discourse by other, and the ideology highlights the extent to which the language relies upon common-sense assumptions. In other words, the ways in which speeches can be ideologically shaped by relations of power. In this sense, there is coherence between the way an individual represents the world and the way of the world could be "meant, constituted, and constructed' by him/her. Grounded on this principle, we were able to understand how some health practices and policies (exclusive breastfeeding) or some social place (hospital or home) and people (healthcare professionals, family members and neighbors) could dominate mothers' discourse. In other words, how the utterances from each mother's group embodied the hegemony of medical discourse and the ideology of scientific knowledge regarding exclusive breastfeeding. Furthermore, it also expressed the hegemony of family and community discourses and the ideology of local knowledge regarding infant feeding. 


\section{FINDINGS}

In this section, we present the findings in two parts. In the first, we describe information regarding breastfeeding strategies, procedures, and techniques provided by healthcare professionals. In the second part, we explain the mothers' experience with infant feeding at home. We also tried to understand how the exclusive breastfeeding, based on medical knowledge, learned at KM-Unit were applied to the mothers' practicing with infant feeding at home setting. Among the eleven groups of mother, six were breastfeeding and supplementing with formula, three were using formula feeding and supplementing with breastfeeding, and two were only using formula feeding as a source of infants nutrition.

\section{1) The teaching-learning process in the Kangaroo Mother Method: mothers preparing for the initiation of breastfeeding.}

The mothers' knowledge regarding breastfeeding and caring for their infants were initially acquired during their temporary stay in two different hospital settings: the Kangaroo Mother Method at critical care unit (CC Unit) and Kangaroo Mother Unit (KM-Unit). The length of hospital stay (minimum of 15, maximum of 55 days) contributed to the implementation of the teaching learning process developed in the medical context of knowledge and practice.

As a medical intervention, the kangaroo method was perceived as very demanding by G's mother: "It is really boring staying at the KM-Unit. Imagine spending more than a month inside a hospital (she stayed 55 days in total), having nothing to do. I wasn't sick."

By immersing in this medical intervention, mothers recognized that the Method was a strategy for their infants' survival and well-being. G's mother continued talking about her experience in the unit: "... I chose to stay because I thought... 'I'll do what is the best for the well-being of my child'."

Not only did the Kangaroo Mother Method involve specific clinical guideline for the infants' survival, it also offered a proper environment for mothers participating in a formal teaching learning process. During their stay, every mother was taught how to manage breastfeeding procedures, strategies, and techniques.

For example, the animator (nurse) questioned mothers on the procedures for extracting, and draining breastmilk by pumping as she had learned at the very beginning of their hospital stay. M's mother replied: "At the CC-Unit, nurses helped me to pump milk. Y' know? Then, I would put the milk in a glass container ..."

Under the medical context of implementing the Method into the critical care setting (CC-Unit), mothers observed different strategies for providing breastmilk to their infants. M's mother continued her narrative: " . . and they fed him... by feeding tube or plastic cup."
Whenever the mothers' breastmilk was insufficient, they were taught through observing strategies of giving formula to their infants. Initially, infants were breastfed or fed with the help of formula through feeding tubes. The latter strategy was used when the woman was physiologically unable to produce sufficient milk to supply the infant's premature and low birth weight needs. As J's mother said: "At the hospital, I didn't have enough milk for him, he cried and cried ... There, at the Kangaroo Unit, he was given another kind of milk (formula) by feeding tube or plastic cup."

Once infants were able to suckle on the breast, achieve better clinical status, and gain enough weight $(1.250 \mathrm{~g})$, they were transferred from critical care setting to KM-Unit.

In their narratives, mothers clearly mentioned the guidelines to follow while breastfeeding infants with special needs thereby illustrating the strength of the medical context in transferring new scientific knowledge and feeding patterns to mothers. For example, J's mother highlighted: "At the Kangaroo Mother Unit (KM-Unit), at first, it was difficult because he suckled but no milk came out [...] Little by little, with the help of the nurses, he started latching on the nipple better."

In addition, at the KM-Unit, the continued closeness between mothers and infants grew and emphasis was placed upon the intensive teaching-learning process for exclusive breastfeeding. Further, J's mother mentioned: ". . .At Kangaroo Mother (unit), he was always with me; getting stronger, and then starting to suckle harder..."

According to a twins' mother at the KM-Unit, she was taught the strategies for breastfeeding her infants. In her own words: "While I breastfed M1, M2 stayed in the incubator. After, the nurse brought me $M 2$, she returned $M 1$ to the incubator. It was a good experience."

She also learned how to hold up each twin (tied around her in the kangaroo position) as well as to breastfeed and take care of them. During the time she spent at the hospital, efforts were made to emphasize the learning-teaching process of exclusive breastfeeding with the support of healthcare professionals. Once the infants showed good suckling patterns and were exclusively breastfed, they were discharged from the hospital setting.

During the infants' process of transition feeding, mothers learned the technique of breastfeeding; how the baby should latch-on, suckle on the breast, and the more comfortable position to do it. As K's mother stated: "Sometimes, [... ] I give her my breast while lying down sideways. The way I learned at the Kangaroo Mother Unit."

The more mothers learned about procedures, strategies, and techniques related to infant feeding, the more confident they were to adopt breastfeeding as the main source of ISHCNs' nutrition and hydration. Consequently, both mothers and infants became stronger as they practiced breastfeeding on a daily basis following the guideline of the Kangaroo Mother Method at CC-Unit and KM-Unit. Mothers also perceived that all efforts were made to ensure their infant's progressive weight gain, 
which represented an important rational explanation for initiating breastfeeding in the hospital setting. But, how the medical knowledge regarding exclusive breastfeeding, learned by mothers in the hospital context, was implemented to the infant feeding at home?

\section{The disembodiment of medical knowledge on breastfeeding infants in their familial and community contexts.}

Once mothers returned home, they acquired additional cultural knowledge from their family and community; for instance, by adding water as a source of infants' hydration. J's mother, contradicting herself in reply to the animator (nurse): "I only give him my breast (at home). Only now, he's starting to like water a little. Before that, he didn't (like it) [...] Sometimes, I wonder whether he was satisfied or not with only nursing..."

The cultural practice of providing water to the infant is based on the belief that breastmilk is only for satiated hungry, but not thirsty. This cultural knowledge replaced the medical knowledge of exclusive breastfeeding as a source of providing nutrition and hydration to all infants.

Her contradiction remains within the fact that "exclusive breastfeeding" has a different meaning from "only breast." The differential use of language may lead to misunderstand if one does not consider the context carefully. That is, while "exclusive breastfeeding" means breastmilk as the only source of infants' hydration and nutrition for healthcare professionals. On the contrary, into the family environment, the term "only breast" means that breastmilk represents the exclusive source of the infants' nutrition, and it is not a source of hydration. Thus, in the minds of mothers and family members, "only breast" does not mean the same thing as "exclusive breastfeeding."

Moreover, our field work observations indicated that three grandmothers were using formula as a supplement to breastfeeding. For example, J's Grandmother remarked: “. . . When he continues crying... (Looking at J's mother) ... I prepare a little formula, fill the bottle (she demonstrated the portion separating thumb and index), and he drinks like there will be no tomorrow!"

This data suggested that the voices and actions of family members regarding infant feeding became more powerful than the initial knowledge acquired by mothers in the medical context. On the one hand, the mother's voice was one among the collective and that was in contradiction with the medical knowledge that they previously learned. On the other, what mothers were taught in the medical context did not express that they gained enough meaningful knowledge to negotiate and share with others in the context of their lives.

Fur thermore, the following mother's narrative highlighted that, at home, there was a lack of health education provided by healthcare professionals. F's Mother said: "One of my nipples was a little sore (thrush), but then I would avoid giving her the breast that was sore and would only give her the one which wasn't. Then it got better. When it is painful I give her formula little by little with the help of plastic cup."

The strategy by which mothers manage their infants' feeding and care at home represents a fusion of medical knowledge brought by them from the hospital (e.g., plastic cup), and popular knowledge that came from the experience of the inner family circle (e.g., regular formula prepared by family members without a physician's prescription). This fusion of medical and popular knowledge is a vealed alliance between mothers and family members in the benefit of the infants' wellbeing which is measured by his/her appearance of satisfaction, calm sleep and weight gain.

This data also indicated that breastfeeding practices require continuous health education and healthcare professional intervention regardless of the setting (critical care or kangaroo mother unit) - or social space (hospital or home). But, once at home, new challenges (e.g., thrush) push mothers up face-toface with barriers to exclusively breastfeeding (e.g., soreness, pain). Thus, in her specific situation, the more practical solution was to interrupt breastfeeding and introduce formula as a source of nutrition. Conversely, the same healthcare professional orientation, available in the hospital environment for initiating breastfeeding, was not available if and when clinical occurrences happened at home. Despite the fact that at the hospital, mothers set a protective alliance with healthcare professionals, based on motherhood outcomes for infants' ill-being; it seems that its alliance did not work in the context of home.

On the one hand, scientific knowledge empowered mothers for caring and exclusive breastfeeding of their infants with special health needs; on the other, the daily life of breastfeeding without continued health education disclosure the necessity of additional information and action which were replaced by those of the extended family in the community context.

In addition, the following dialogue (continued from above) illustrates the lack of familial knowledge to deal with thrush. F's Grandmother added: "It's really hard to breastfeed with this sore on the breast. Whenever, F. latches-on, my daughter cried. I don't know how to help her... Then, I prepared formula and she stopped putting her on the breast."

Neither mother nor family member had adequate knowledge for providing a suitable approach in the event of thrush. Furthermore, the absence of healthcare professional action (health education and/or immediate clinical intervention), gradually disempowered the mothers' medical knowledge regarding exclusive breastfeeding and empowered familial popular knowledge related to formula feeding.

Although at home, they could use some aspects of the medical knowledge brought back from hospital (feeding by plastic cup, pump breastmilk), the meaning of these words was disembodied from their everyday life, and popular knowledge within their social environment relating to care and feeding led to the discontinuation of exclusive breastfeeding. 
Another narrative confirmed the alliance between mothers and community members through the adoption of a fused knowledge in order to be accepted as a member of their social group. In spite of the fact that K's mother had plenty of breastmilk, she occasionally fed formula to $\mathrm{K}$ or breastmilk by bottle, because the early weaning process had already started: "When she doesn't want the other kind of milk (formula) prepared by my next neighbor, I even pump my breastmilk to put in the bottle so that I can give it to her later. You know, so I won't throw everything out. Sometimes I even throw it out."

Despite the fact that mothers returned once a week for a follow-up consultation with a physician during the first month after discharge from Maternity Centre, they abandoned the practice of exclusive breastfeeding. O's mother (nuclear family) adopted breastfeeding as a supplement to formula feeding, by negotiating with the physician: "I realized I was dry. The physician I talked to in the follow-up consultation prescribed E. (soy milk) for supplementing breastfeeding, just in case she cried a lot... You know, her weight was always fluctuating."

Breastfeeding supplemented by formula was adopted by 0 's Mother as a source of her infant's nutrition based on an unrealistic medical prescription but also to justify her intention to continue offering their breasts for financial reasons. The animator (nurse) questioned: "Why do you give her formula, after she breastfed? This formula is too expensive. Did she have any health problems?" R's Mother answered: "No! My breasts weren't swelling anymore. . . like they were at the MC. I squeezed, nothing came out. She always cries, wanted more. I need to work otherwise my two children and I will be penniless!"]

Mothers felt simultaneously empowered and disempowered with this medical advice and prescription. On the one hand, she confirmed that she has insufficient breastmilk for pumping, storage, and feeding in her absence. Further, this recommendation did not fit in her financial situation. The prohibitively high cost of soy milk, in comparison to the Brazilian minimum wage, meant that she could not afford it. Consequently, when the mother was absent from home and working in the nonformal labor market, in addition to the fact that she had no right to maternity leave, giving formula was the alternative to breastfeeding the infant. As a creative strategy within the community context, neighbors exchanged babysitting and provided infant feeding (formula or breastmilk left by mother) while the other was working. There is solidarity among poverty women in low income homes during work days.

This empowerment-disempowerment process generated a set of elements, often times contradictory, such as communication and lack thereof, happiness and sadness, hope and hopelessness. However, even though these elements and feelings oppose each other, they are not completely independent.

The following mother's narrative also illustrated how difficult it was to implement exclusive breastfeeding for her twins at home without continuous health education provided by healthcare professionals. In the case of the twin's mother, she looked anxious and tired because she could not manage her infants' refluxing and burping all night long. When we visited her, she reported: "Babies nurse, sleep for a while, and then want more. I give them a little more and immediately they start refluxing. Even after burping, I seat them for a while. At night, it is harder."

Formula feeding was the source of nutrition adopted by C's family because the infant's mother had to return to work far away from home. Thus, formula was prescribed by the physician. C's grandmother: "Because my daughter works far away from here and couldn't breastfeed him, in the second follow-up consultation the doctor prescribed formula. He's doing very well. When she's at home she breastfeeds him."

Despite the fact that eleven mothers were exclusively breastfeeding after being discharged from the hospital setting, our data revealed that, once at home, they had adopted mixed and formula feeding as a source of infant feeding. The findings also highlighted three different styles of infant feeding using both types: breastfeeding added by water and herbal tea, breastfeeding supplemented by formula feeding; formula feeding supplemented by breastfeeding, and only formula feeding.

\section{DISCUSSION}

The formal teaching-learning process of breastfeeding developed at the KMM hospital was essential for the initiation of exclusive breastfeeding. When the woman's body is capable of providing milk, initiated by the process of an electrical and manual pump at the Breastmilk Bank ${ }^{(15)}$ the breastmilk becomes a major source for infant feeding in the medical context of the KMM. It also represents the first concrete initiative of promoting breastfeeding for mothers and ISHCNs. The first stage of transitional infant feeding started with breastmilk; formula was provided as an alternative nursing source when there was not enough breastmilk for the infants' need. This was done by feeding tube and/or plastic cup. In the second stage, breastmilk was provided by plastic cup or feeding tube and supplemented by breastfeeding. Finally, when suckling and swallowing reflexes were assessed to be adequate by healthcare staff (physician, nurse, speech therapist) and the infants were considered neurologically mature, breastfeeding was supplemented by breastmilk given with the help of plastic cups. This guideline is recommended by $\mathrm{WHO}^{16}$ and followed by the Brazilian policy of the Baby Friendly Hospital ${ }^{15}$ and Kangaroo Mother Method intervention'.

In spite of the efforts made in promoting exclusive breastfeeding under clinical control and intensive teachinglearning process, mothers experienced a discontinuation in their access to health education in the context of their community once they were discharged from the medical context. In addition, they experienced an interruption in the constant flow of information received from healthcare professionals which was 
then replaced, in the context of their home, by non-formal information and procedural knowledge received by their family members.

Despite the teaching-learning process of breastfeeding procedures, strategies and technique is the cornerstone in promoting the successful initiation of breastfeeding ${ }^{(17-19)}$, it does not guarantee the continuation of this practice at home. Mothers embodied exclusive breastfeeding as a behaviour only in the first moment of maternal care. Paradoxically, the unintentional exclusion of family members during this first moment contributed to the interruption of exclusive breastfeeding and disempowered medical knowledge brought by mothers from medical setting; subsequently, a new behavior replaced exclusive breastfeeding for ISHCNs. If family members were to be included in the teaching-learning process for exclusive breastfeeding developed at Kangaroo Mother Method, this would help mothers avoid being placed in a contradictory situation and extend the practice beyond the hospital setting.

The fused knowledge (popular and medical) also gave a new perspective to the maternal care grounded on scientific motherhood of low birth weight and premature infants. In addition, it depicted a social construction mediated by the formal learning-teaching process developed at KMM, and nonformal, at home. Regardless of whom mothers did the alliance with (family members, neighbors or healthcare professionals), sometimes, it could be hazardous to the ISHCNs health, whose growth and development follow a different pattern of the full term infants. They are more clinically fragile $e^{3-4}$ than the latter group of newborns.

In addition, the health education gap between the medical and family contexts allowed us to understand how inconsistent breastfeeding was learned among the eleven groups of mothers and their family members who lived in low income communities of Rio de Janeiro. Bittencourt et a/ ${ }^{18}$ found that, among the same population in Rio de Janeiro, $98.88 \%$ of mothers were exclusively breastfeeding upon discharge from the hospital setting. After one month, this rate fell to $44.88 \%$. This illustrates the weak impact of the teaching-learning process developed at the hospital setting upon the extent of exclusive breastfeeding at home. It also reveals the necessity to implement health education at the familial and community settings.

As a result of the social practices of feeding and care of premature and low birth weight, either at hospital or at home, new knowledge was learned and embodied by mothers' immersion. In the hospital setting, the teaching-learning process provided by healthcare professionals, as well as the observation of their practices, taught mother how to care for and breastfeed his/her infant. The reality at home was unknown and needed to be unveiled, especially after the KMM experience of promoting breastfeeding. The change from hospital to the home setting determined a different sociocultural context of breastfeeding. In the context of medical practice (i.e., at the hospital) breastfeeding was implemented as a clinical guideline connected to the Method. However, in the context of family and community, breastfeeding acquired another meaning; that is, it was disconnected from the Kangaroo Mother style of infant care. Being aware of these issues could contribute to a new health policy for infant care by considering the sociocultural context of the mother's life which assumed an important role in breastfeeding after the Kangaroo Mother Method experience.

Healthcare professionals (psychologists, nurses, physicians, pediatricians, social workers, speech therapists) provided support and scientific information regarding the health care of infants with special health needs. These infants were the main focus of the Kangaroo Mother Method with mother being responsible for implementation. Scientific discourse mediation at the Method in favour of exclusive breastfeeding was confronted with family discourse for breastfeeding in a nonexclusive manner at home. Our findings highlighted the necessity of improving the quality of care at home by providing continuous health education, healthcare professional intervention based on the reality of family and community, as well as including family members in the Method. We do believe that these actions can contribute to the quality of life of these infants with special health needs who are clinically fragile, dependent on intensive family and medical care for their survival ${ }^{3-4}$.

Family members and neighbors shared knowledge regarding full term infants' replacement of breastfeeding by formula feeding in full term infants. Such knowledge and practice is sometimes not appropriate for either infants with special health needs or for full-term babies. Often, this lack of popular knowledge ${ }^{19}$ related to proper infant feeding for these infants intersected that of the breastfeeding medical knowledge (through the Kangaroo Mother Method intervention) brought home by mothers. As a result, the exclusive breastfeeding was discontinued.

Said otherwise, what was taught at Kangaroo Method did not mean that mothers learned or could apply in their actual context of living. At the same time, exclusive breastfeeding need to be recognized as biological ability and culture understanding, due to it is grounded on the social systems of meanings. Consequently, why do women stop breastfeeding need to be understood through immersion in their sociocultural environment rather than by assuming a neutral position regarding this reality and it impact on the morbidity and mortality during in the first year of infants' lives.

\section{CONCLUSIONS, IMPLICATIONS FOR INFANTS NEEDS HEALTH PRACTICES}

The knowledge taught to mothers at kangaroo care, with respect to exclusive breastfeeding of infants with special health needs, was not embodied into the inner family circle in that none of eleven mothers were implementing it one month after being discharged from Maternity Centre. We identified: 1. a gradual disappearance of teaching-learning process; 2 . the lack of health education at community setting; 3 . follow-up 
consultations restricted to physician interventions in outpatient setting and; 4. the non implementation of the method at home in the Rio de Janeiro healthcare context.

The mother's knowledge regarding infant feeding methods and the care of premature or low birth weight babies was developed through interaction with healthcare professionals through several means (i.e., teaching-learning process, observation, conversation, consultation) during the stay and/ or visit to the healthcare facility. Further, mothers gained additional popular knowledge simply by living in the context of community and family of low income population who shared the same culture.

On the one hand, we need to recognize that families and community members develop and transmit popular knowledge and practices regarding infant care and feeding based on their own experiences, beliefs, values and meanings. On the other, women seek to articulate their new experience of being a mother (motherhood) of low birth weight and premature infants within systems of meaning (knowledge and practices) from their family and community members as well as the recommendations of healthcare professional.

Our findings also showed that the third stage of Kangaroo Mother Method implemented in the home setting does not occur in Rio de Janeiro while the follow-up consultation is restricted to the outpatient setting. Contrary to the Method in the hospital setting, where the healthcare team participated in promoting and teaching the initiation of breastfeeding, the Method in the outpatient setting is follow-up only by the physician.

\section{REFERENCES}

1. Ministério da Saúde (Brasil). Atenção humanizada ao recém-nascido de baixo peso: método mãe-canguru: manual técnico. Brasília (DF); $2002,196 \mathrm{p}$.

2. Lamy ZC, Gomes MASM, Gianini NO, Hennig MAS. Atenção humanizada ao recém-nascido de baixo peso - método canguru: a proposta brasileira. Ciência e Saúde Coletiva. 2005; 10(3): 659-668.

3.Cabral IE, Moraes JRMM, Santos FF. 0 egresso da terapia intensiva neonatal de três instituições públicas e a demanda de cuidados especiais. Esc Anna Nery Rev Enferm 2003; 7, (2): 211-18.

4. Moraes JRMM, Cabral IE. 0 cuidar de crianças egressas da unidade de terapia intensiva neonatal no espaço domiciliar: instrumentos mediadores das famílias. Texto\& Contexto Enferm 2004; 13(3): 45258.

5. Campos MA, Cabral IE. Concepções e vivências das mães na enfermaria mãe canguru-subsídios para prática de enfermagem pediátrica. Rev Soc Bras Enferm Pediatr 2002; 1(2): 37-8.

6. Moss W, Darmstadt GL, Marsh DR, Black RE, Santosham M. Research priorities for the reduction of perinatal and neonatal morbidity and mortality in developing country communities. J Perinatol 2002; 22: 484-95.

7. Conde-AgudeloA, Diaz-Rossello JL, Belizan JM. Kangaroo mother care to reduce morbidity and mortality in low birthweight infants (Review). The Cochrane Collaboration. Wiley; 2005.
Moreover, in the latter setting, the usual intervention developed to monitor infants' health is usually based on the control of growth and development without the participation of home visit nurse.

Our results suggest that, to achieve better infant health outcomes, nurses need to develop continuous care beyond the medical setting in order to prevent infant morbidity and mortality. In the home and community context, they should provide health education activities as well as support mothers, family members and neighbors so as to continue exclusive breastfeeding and care of infants with special health needs The whole family should be involved in the Kangaroo Mother Method and not only mother.

We also recommend the implementation of health education for all members of the community. The rationale for including the whole family and neighbors in the health education interventions regarding breastfeeding promotion is based upon the necessity of improving infants' health as well as prevention disease during the post-neonatal period

Furthermore, the hospital has to establish a connection with other health facilities ${ }^{(13)}$ (such as Community Health Centre), and program (Brazilian Family Health Program) and community-based, in order to provide health promotion strategies for mothers and infants.

Unless global Brazilian interventions, designed to improve the health of infants, take into account contextual barriers to exclusive breastfeeding, it is unlikely to expect any improvement in the current high infant morbidity and mortality rates in the first year of life.

8. Ministério da Saúde (BR). Caderno de Informação de saúde. Informações gerais. Secretaria Executiva: Ministério da Saúde. Disponível em: http://tabnet.datasus.gov.br/tabdata/cadernos/BR/ Brasil_GeralBR.xls. Acesso em 29 de marco de 2005.

9. Ministério da Saúde (BR) Secretaria de Atenção a Saúde. Departamento de Ações Programáticas Estratégicas. Agenda de compromissos para a saúde integral da criança e redução da mortalidade infantil. Brasília (DF); 2004.80 p.

10. Apple RD. Mothers and medicine: a social history of infant feeding 1890-1950. Wisconsin(USA): University of Wisconsin Press; 1987.

11. Denzin NK, Lincoln YS The Sage Handbook of Qualitative Research. $3^{\text {rd }}$ ed. California (USA): Sage; 2005.

12. Cabral IC. Método criativo e sensível. In: Gauthier, JHM; Cabral IE; Santos, I.; Tavares, CMM. Pesquisa em enfermagem. novas metodologias aplicadas. Rio de Janeiro (RJ): Guanabara Koogan; 1998.

13. Freire P. The pedagogy of the oppressed. 30th ed. New York; (USA): Continuum; 2006. 183p.

14. Fairclough N. Language and power. $2^{\text {nd }}$ ed. Harlow:Pearson Education; 2001.

15. Ministério da Saúde (BR). Secretaria de Políticas de. Secretaria da Criança e Aleitamento Materno. Departamento de Gestão de Políticas Estratégicas. Recomendações técnicas para o funcionamento de bancos de leite humano. $4^{\mathrm{a} e d .}$ Brasília (DF); 1999. 
16. World Health Organization. Kangaroo Mother Care: A practical guide. 2003. Geneva: Department of Reproductive Health and Research. World Health Organization. 54p.

17. Valdés V, Schooley J. The role of education in breastfeeding success. Food and Nutrition Bulletin. 1996. [Access 2006 July 6]; 17(4): 10. Available in: http://www.unu.edu/unupress/food/8F174e/ 8F174E0m.htm..

\author{
Cabral IE, Groleau D
}

18. Bittencourt S A, Leal MC, Jourdan-Gadelha AM, Oliveira MA. Growth, Diarrhea, and breastfeeding: the case of Vila do João. Cad Saude Pública 1993; 9 (suppl 1): 07-13.

19. Esterik PV. The cultural context of breastfeeding and breastfeeding policy. Food and Nutrition Bulletin. 1996; [Access 2006 July 6] 17(4): 11. Available in http://www.unu.edu/unupress/food/8F174e/ 8F174EOm.htm..

20. Ahluwalia IB, Morrow B, Hsia J. Why do women stop breastfeeding? Paediatr 2005; 116(6): 1408-412.

\section{NOTES}

a Study funded by the National Council for Research Development (Conselho Nacional de Desenvolvimento Científico e Tenológico/ CNPQ.). Postdoctoral Fellowship 2005-2006. 